\title{
Evaluation and Optimization of Bypassed Oil in Carbonate Reservoir at Mature Field with Integration of Saturation Log and Cement Bond Quality
}

\author{
Agus Amperianto'), Dyah Rini Ratnaningsih' ${ }^{2)}$, Dedy Kristanto ${ }^{2)}$ \\ 1) PT. Pertamina \\ 2) Petroleum Engineering Department UPN "Veteran” Yogyakarta \\ *corresponding email jakfarjakpres@gmail.com
}

\begin{abstract}
AA field is a unitized asset operated by Corporate Oil Company since May 2018. The main producing formation of AA field is a reef build-up carbonate reservoir. The field has been on production since 2004 with OOIP of 297 MMSTB. As of November 2019 the cumulative production was estimated 120.7 MMSTB with RF of $41 \%$. The carbonate reservoir has properties with relatively high heterogeneity -both vertically as well as laterally - which leads to production variation of the wells. The production performance shows an estimated $30 \%$ decline and significantly increasing water-cut. The production data shows a much faster water production compared with the cumulative production, which is also the greatest challenge in the AA field.
\end{abstract}

There are several key contributing factors for the water production in AA field:

1. Water channeling behind casing due to poor cement bond. This is supported by Chan Plot analysis.

2. Uneven production of the wells leading to varying water rise and introduces difficulty in water contact determination.

3. Water coning due to production exceeding the critical rate.

Several efforts have been performed to optimize production, namely: identification of the potential of remaining hydrocarbon (bypassed oil) in the wells by evaluating current saturation evaluation through downhole surveillance, estimation of current water contact and cement bond improvement.

The preparation steps of the production optimization process are summarized below:

1. Screening of Candidate Wells

2. Evaluation of Cement Bond Quality

3. Wellsite Execution for Bypassed Oil Evaluation

- Well Preparation

- Optimum C/O Log to Evaluate Current Saturation and to Identify Bypassed Oil Zones

4. Bypassed Oil Interval Production

This section discusses one of successful cases in the production optimization effort implemented in the AA- field.

AA-12 well

The last production of AA-12 well was 84 BOPD. Chan plot showed possibility of water channeling, which was supported by CBL result. The zone of existing perforation interval was indicated to have "free pipe" behind the casing. Remedial cementing was then performed until sufficient zonal isolation was obtained. After subsequent CBL confirmed good zonal isolation, $\mathrm{C} / \mathrm{O} \log$ was then performed. The $\mathrm{C} / \mathrm{O} \log$ result indicated several reservoir zones with potential bypassed oil. The new production interval was selected based on following consideration: So between 55-60\%, height above current OWC of $185 \mathrm{ft}(56 \mathrm{~m})$, distance to the adjacent wells of $1306 \mathrm{ft}(398 \mathrm{~m})$, porosity 12-17\% and Production test of the new perforation resulted in 2186 BOPD with $0 \%$ water-cut.

Keywords: Carbonate Reservoir, water channeling, oil saturation, water saturation, cement bond

\section{INTRODUCTION}

AA field is a unitized asset operated by Corporate Oil Company since May 2018. The main producing formation of AA field is a reef build-up carbonate reservoir. The field has been on production since 2004 with OOIP of 297 MMSTB. As of November2019 the cumulative production was estimated 120.7 MMSTB with RF of $41 \%$. The carbonate reservoir has properties with relatively high heterogeneity -both vertically as well as laterally - which leads to production variation of the wells. The production performance shows an estimated 30\% decline and significantly increasing water-cut. The production data shows a much faster water production compared with the cumulative production, which is also the greatest challenge in the AA field can be seen in Figure 1. The significant increase in water-cut and combined with the fractional flow data from SCAL (Special Core Analysis) data show promising chance of production optimization. 

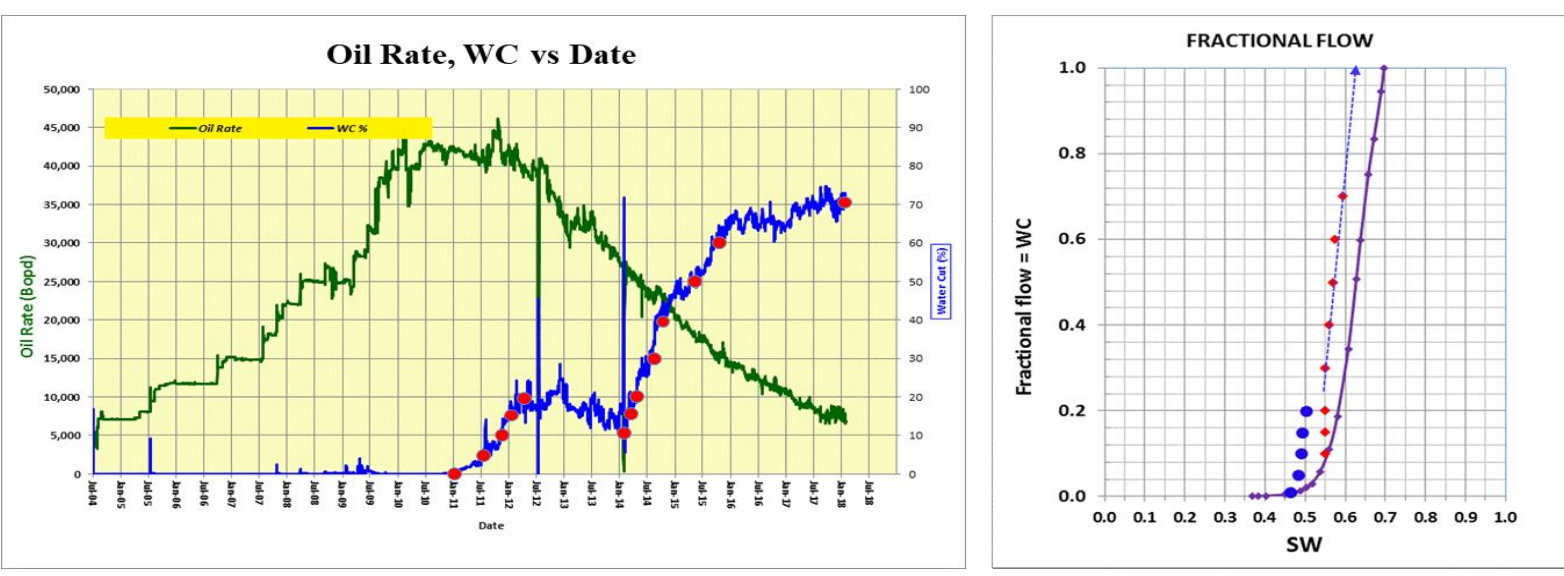

Figure 1. Production Performance and Fractional Flow of AA Field

From the above-mentioned observation, there are several key contributing factors for the water production in AA field:

4. Water channeling behind casing due to poor cement bond. This is supported by Chan Plot analysis.

5. Uneven production of the wells leading to varying water rise and introduces difficulty in water contact determination.

6. Water coning due to production exceeding the critical rate.

Several efforts have been performed to optimize production, namely identification of the potential of remaining hydrocarbon (bypassed oil) in the wells by evaluating current saturation evaluation through downhole surveillance, estimation of current water contact and cement bond improvement.

\section{METHODS}

Bypassed oil is defined here as the mobile oil that cannot be produced by existing layer and will be left undrained if nothing is done (Choon, 2007). For the case of AA field, the bypassed oil is mostly related to reservoir properties heterogeneity. The identification of bypassed oil is performed through downhole surveillance, specifically cased hole $\mathrm{C} / \mathrm{O}$ $\log$ tool. The preparation steps of the production optimization process are summarized below:

\subsection{Screening of Candidate Wells}

The screening process is aimed at identifying high priority wells as production optimization candidates. This done by analysis on RF for the well (with assumption of 250-m drainage radius) with a cut-off value of $53 \%$ based on SCAL data. Wells with the lowest RF will be on top of the priority list. From this starting point, identified wells are further screened based on criteria, such as reservoir position with respect to the estimated current oil-water-contact, shut-in wells, wells with very low production rate or high water-cut. In addition to the above, in the context of fieldwide surveillance, wells were selected to cover the subsurface crest and flange.

\subsection{Evaluation of Cement Bond Quality}

In wells drilled into the reef build-up reservoir, often characterized by caving and vuggy-porosity, it is a common occurrence to have bad cement bond and even "free-pipe" due to non-optimal cementing. The remedial cementing plan was put in place to improve cement bonding to provide sufficient zonal isolation preventing water channel if there are water zones below the prospective oil-bearing layers. Additionally, the well-cemented annulus can also help reducing the uncertainty of cased hole saturation evaluation by $\mathrm{C} / \mathrm{O} \log$ related to borehole condition.

\subsection{Wellsite Execution for Bypassed Oil Evaluation}

The wellsite execution consists of the following activities:

\subsubsection{Well Preparation}

The well preparation activity starts with pulling out the existing production string, drilling out plugs, remedial cementing and wellbore clean-out prior to cased hole logging. Cement bond logging was then performed to evaluate the result of remedial cementing. Key criterion for a successful remedial cementing is sufficient zonal isolation, especially between potential hydrocarbon zones, existing production zones and nearby water-bearing zones. The remedial cementing could be repeated if that criterion had not been satisfied. 


\subsubsection{Optimum C/O Log to Evaluate Current Saturation and to Identify Bypassed Oil Zones}

The C/O log was first introduced in the 1970s and basically built upon the pulsed neutron technology platform (Culver, R.B., et al, 1974). The technology has since then gone through further development in terms of data interpretation (Mickael, M.W. et all, 1997) and instrumentation (Gilchrist, Jr. W.A, et all, 1999). Nowadays it has become one of the well-established downhole surveillance methods for hydrocarbon saturation evaluation.

Two key factors in formulating an optimum $\mathrm{C} / \mathrm{O} \log$ are related to log interval selection and number of logging passes. The log interval was selected to also include water zones, which can be used to validate $\mathrm{C} / \mathrm{O}$ log result in actual borehole condition. Multiple passes of $\mathrm{C} / \mathrm{O} \log$ are required since $\mathrm{C} / \mathrm{O} \log$ measurement is inherently statistical.

\subsubsection{Bypassed Oil Interval Production}

The ultimate step of production optimization in the AA field is targeting potential bypassed oil zones by means of perforation. The following describes the workflow in selecting potential bypassed oil zones for perforation:

- Based on $\mathrm{C} / \mathrm{O} \log$ result, an oil saturation cut-off $>30 \%$ was used to identify potential bypassed oil zones. This oil saturation cut-off was chosen since it is in accordance with fractional flow from SCAL data of AA field.

- Height above current OWC. With increasing height above current OWC, the likelihood for water coning to occur will be low.

- Distance of one reservoir unit to the adjacent wells. Even though there is lateral heterogeneity of reservoir properties in AA field, radius of $820 \mathrm{ft}(250 \mathrm{~m})$ was thought to be a safe-distance to avoid inter-well communication.

- Rock type and porosity were also considered in selecting potential bypassed oil zones. If the potential bypassed oil zones are not classified as good quality rock type with high porosity and high permeability, subsequent stimulation (i.e. acidizing) was planned.

\section{RESULTS AND DISCUSSION}

This section discusses one of successful cases in the production optimization effort implemented in the AA field.

\section{AA -12 well}

The last production of AA-12 well was 84 BOPD. Chan's plot showed possibility of water channeling, which was supported by CBL result. The zone of existing perforation interval was indicated to have "free pipe" behind the casing. Remedial cementing was then performed until sufficient zonal isolation was obtained. After subsequent CBL confirmed good zonal isolation, $\mathrm{C} / \mathrm{O} \log$ was then performed. The $\mathrm{C} / \mathrm{O} \log$ result indicated several reservoir zones with potential bypassed oil. The new production interval was selected based on following consideration: Oil saturation (So) between $55-60 \%$, height above current OWC of $185 \mathrm{ft}$ (56 m), distance to the adjacent well of $1306 \mathrm{ft}$ (398 m), porosity 12-17\% and Rock Type 1. Production test of the new perforation resulted in 2186 BOPD with $0 \%$ water-cut, can be seen in Figure 2.

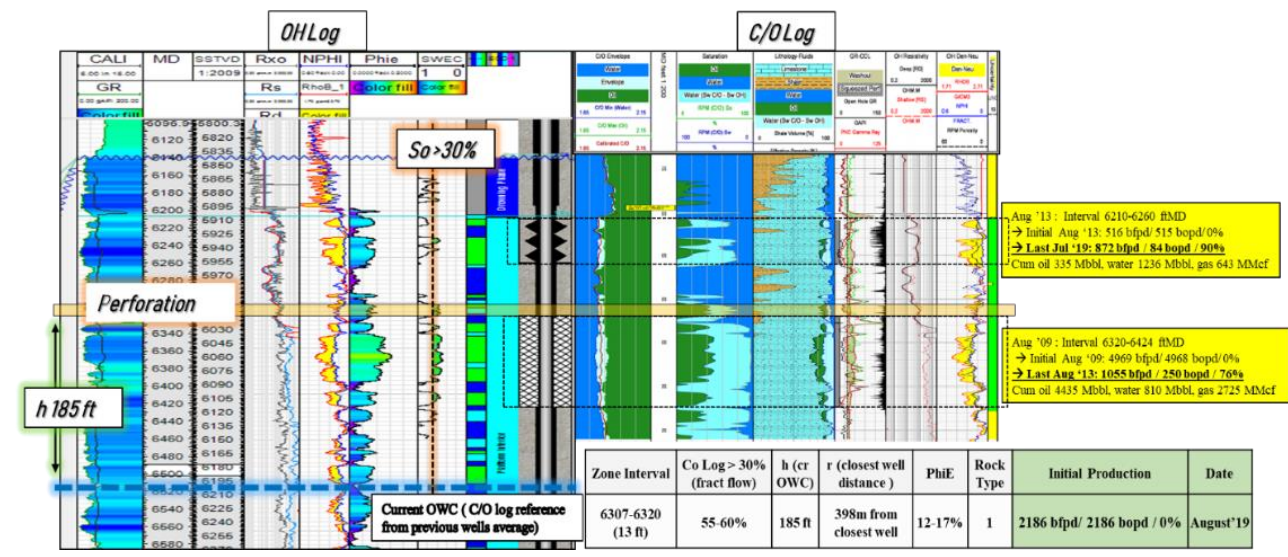

Figure 2. AA-12 Open hole log and C/O Log result with the new production interval marked by orange box

From the total of seventeen wells, fourteen wells were successfully re-perforated and put on production with incremental gain of approximately 10000 BOPD. The probability of successful identification and production of bypassed oil is roughly 
$82 \%$. Several wells were not successful to produce additional gain due to possible caving within the reservoir structure, which lead to total losses in remedial cementing and preventing subsequent production of the reservoir fluids.

Another important information resulting from $\mathrm{C} / \mathrm{O} \log$ surveillance in wells in the AA field is the current OWC, which was estimated at depth $6200 \mathrm{ft}(1890 \mathrm{~m})$ TVDSS. This information helps to explain low oil production and high watercut for wells with producing zones located below the current OWC.

\section{CONCLUSIONS}

1. The AA field with main producing reservoir comprises of reef build-up carbonate has high vertical and lateral heterogeneity. The field is already considered a mature filed with RF of $40 \%$.

2. There were four key steps in the production optimization effort in AA field related to bypassed oil, namely: screening of candidate wells, evaluation of cement bond quality, wellsite execution of bypassed oil identification and bypassed oil zones production.

3. The identification of bypassed oil by $\mathrm{C} / \mathrm{O} \log$, which was integrated with remedial cementing to improve zonal isolation has proven to be successful in the AA field with $82 \%$ success rate.

4. One limitation of successful identification and production of bypassed oil zones is related to possible caving in the reservoir structure, which is not unusual for reef build-up carbonate reservoirs. The caving structure is likely to be a total-loss zone, which reduces the effectiveness of $\mathrm{C} / \mathrm{O} \log$ measurement and also prevents subsequent production of the reservoir fluids.

\section{REFERENCES}

Choon, Tan Teck [2007]. Identification of Bypassed Oil For Development In Mature Water-Driver Reservoirs. SPE 10907, 2 p.

Chan, K. S., [1996], Water Control Diagnostic Plots, SPE 30775, Society of Petroleum Engineers Annual Technical Conference and Exhibition, Dallas, USA.

Culver, R.B., Hopkins, E.C. and Youmans, A.H. [1974]. Carbon/Oxygen (C/O) Logging Instrumentation. SPE-AIME 48 ${ }^{\text {th }}$ Annual Fall Meeting.

Gilchrist, W.A., Prati, E., Pemper, R., Mickael, M.W. and Trcka, D. [1999]. Introduction of a New Through-Tubing Multifunction Pulsed Neutron Instrument. 1999 SPE Annual Technical Conference and Exhibition.

Mickael, M.W., Gilchrist, Jr., W.A., Mirzwinski, R.J., Salaita, G.N. and Rajasingam, R.T. [1997] Interpretation of the Response of a New Through-Tubing Carbon/Oxygen Instrument Using Numerical Modeling Technique. SPWLA $38^{\text {th }}$ Annual Logging Symposium.

Rukmana, D., Kristanto, D., Permadi, A.K, Cahyoko Aji, D., [2020], Peningkatan Produksi Lapangan Minyak Tua (Teori dan Aplikasi), Penerbit Pohon Cahaya, Yogyakarta.

Qifei Huang and Yuefeng Sun, Texas A\&M University, October 30, 2017. Carbonate Reservoir Characterization Using the Cementation Factor: A Case Study of Little Cedar Creek Field, Onshore Alabama. 